\title{
The Total Intensity of Geomagnetic Field in Southern China for the Period from 4500 B.C. to A.D. 1500
}

\author{
Q. Y. Wei, D. J. LI, G. Y. CAO, W. X. Zhang, and S. F. WeI \\ Institute of Geophysics, Academia Sinica, China
}

(Received January 6, 1986; Revised April 18, 1986)

\begin{abstract}
The total intensity of geomagnetic field for the period 4500 B.C.-A.D. 1500 was determined with archaeological samples collected from the southern part of China by the Thellier's stepwise heating method. Results indicate that the total intensity of geomagnetic field in this area $\left(28^{\circ}-32^{\circ} \mathrm{N}, 111^{\circ}-120^{\circ} \mathrm{E}\right)$ varied between $38-90 \mu \mathrm{T}$ during the period 4500 B.C.-A.D. 1500 . The high value occurred during the first centuries of Anno Domini with subsequent decreasing while the relative low value was at about 900 B.C. Earlier than 1000 B.C. the average value of the total intensity of geomagnetic field was close to the present day level with evident fluctuations.
\end{abstract}

\section{Introduction}

Great advances in the production of large data sets of ancient geomagnetic field intensity have been made since the excellent work of the Thelliers (THELLIER and THELliER, 1959), especially during the last ten years. There have been published paleointensity data for different parts of the world and attempts have been made to analyse the variation of the field strength with time (SHAW, 1985).

Nevertheless, the amount of intensity data is still insufficient in comparison with direction data, especially since the most continuous and comprehensive declination and inclination records have been coming from lake sediments. After the scarcity of archaeomagnetic data for such a large area as China was noticed some results of both direction and intensity determination have been published (WEI et al., 1980-1984; DENG and LI, 1965). The present paper provides some new results of paleointensity determination for the southern part of China, namely the area around the middle and lower reaches of Yangtze River.

\section{Samples and Measurements}

The Yangtze River valley is one of the birthplaces of China's ancient culture. There are a lot of human relics, tombs, kilns, etc. in this area, which includes Hubei, Hunan, Jiangxi, Zhejiang, Jiangsu provinces. So, baked earth, bricks, tiles and pottery shards useful for archaeomagnetic research are available there. The location of sampling sites is shown in Fig. 1. Among samples collected from this area are some bricks of kilns called "horseshoe", "calabash", "dragon", etc. because of their shape from famous Jingdezhen, Jiangxi province and Longquan, Zhejiang province. Some baked earth specimens were taken from vertical copper-smelting furnace in Tonglushang, Hubei province and from dragon kiln in Yixing, Jiangsu province and 


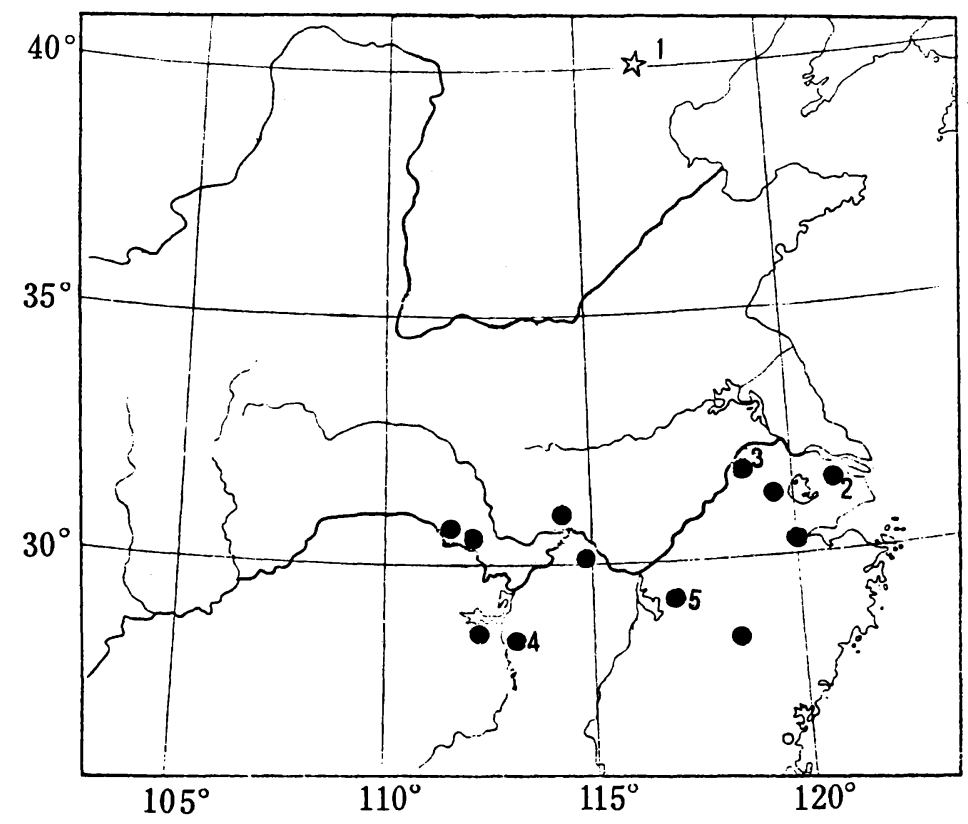

Fig. 1. Map of sampling localities. 1: Beijing, 2: Shanghai, 3: Nanjing, 4: Changsha, 5: Jingdezhen.

other places. As for the pottery ware, only some thick bases or legs of tripod were used.

All data pertaining to samples used in this work are listed in Table 1. A brief description of each site is given along with the archaeologist's estimated age rounded off to decades. Some bricks from tombs or city constructions are carved with accurate dates.

Laboratory measurements of remanent magnetization were made on cubic specimens (30 or $40 \mathrm{~mm}$ edges) using astatic and parastatic magnetometers. The Thellier's method was employed for paleointensity determination. An NRM-TRM diagram was constructed and a line was fitted to appropriate sets of points using the least square method (WEI et al., 1980). The slopes of the fitted lines were used for estimates of ancient field intensity. For every group of samples collected from the same site the average value of ancient field intensity was calculated. Hubei province is located in this area so the paleointensity data for Hubei (WEI, et al., 1983) were included in this paper for discussion.

\section{Results and Discussion}

Experimental results are summarized in Table 1 and some representative NRMTRM diagrams are shown in Fig. 2. Because of the small difference in latitudes the intensity values for different sites in this area are plotted against time together in Fig. 3.

One of the interesting features that is apparent in these results is the maximal value at about A.D. 500 and the gradual decrease of geomagnetic field intensity 
Table 1. Paleointensity data.

\begin{tabular}{|c|c|c|c|c|c|c|c|c|c|c|c|c|c|}
\hline \multirow{2}{*}{$\begin{array}{r}\text { Dynasty } \\
\text { Neolithic }\end{array}$} & \multirow{2}{*}{$\frac{\text { Age }}{5000-4000 \text { B.C. }}$} & \multicolumn{2}{|c|}{$\begin{array}{c}\text { SLA } \\
\left(\mathrm{deg}_{.}, \mathrm{min}\right)\end{array}$} & \multicolumn{2}{|c|}{$\begin{array}{c}\text { SLO } \\
\text { (deg.,min) }\end{array}$} & \multirow{2}{*}{$\begin{array}{l}\text { Sample type } \\
\text { Pottery }\end{array}$} & & \multirow{2}{*}{$\begin{array}{c}F_{0} / F \\
0.92\end{array}$} & \multirow{2}{*}{$\begin{array}{c}S \\
0.03\end{array}$} & \multirow{2}{*}{$\begin{array}{l}F_{0} \\
51\end{array}$} & \multirow{2}{*}{$\begin{array}{l}S_{0} \\
1.7\end{array}$} & \multirow[t]{2}{*}{$M$} & \multirow[t]{2}{*}{$S_{\mathrm{m}}$} \\
\hline & & 30 & 17 & 112 & 13 & & & & & & & & \\
\hline Neolithic & 3000-2600 B.C. & 30 & 26 & 111 & 45 & Baked earth & 3 & 0.98 & 0.01 & 54 & 0.5 & & \\
\hline Neolithic & $2200-1800$ B.C. & 30 & 32 & 111 & 23 & Baked earth & 2 & 0.76 & 0.01 & 42 & 0.5 & & \\
\hline Shang & 1600-1028 B.C. & 30 & 54 & 114 & 23 & Pottery & 4 & 1.06 & 0.02 & 58 & 1.1 & & \\
\hline Western Zhou & 1027- 771 B.C. & 30 & 32 & 111 & 23 & Tripod & 2 & 0.69 & 0.02 & 38 & 1.1 & & \\
\hline Spring-Autumn & $770-220$ B.C. & 30 & 03 & 114 & 58 & Baked earth & 1 & 1.05 & 0.02 & 58 & 1.1 & & \\
\hline Warring States & $480-220$ B.C. & 30 & 21 & 112 & 12 & Baked earth & 3 & 1.08 & 0.07 & 60 & 3.8 & & \\
\hline Western Han & 206B.C.-A.D.8 & 28 & 12 & 112 & 59 & Baked earth & 1 & 0.80 & 0.04 & 44 & 1.8 & & \\
\hline Han & 206B.C.-A.D. 220 & 30 & 21 & 112 & 12 & Grave brick & 4 & 1.39 & 0.03 & 77 & 1.7 & & \\
\hline Han & 206B.C.-A.D. 220 & 31 & 22 & 119 & 48 & Grave brick & 2 & 1.30 & 0.04 & 71 & 2.1 & 13.6 & 0.4 \\
\hline Han & 206B.C.-A.D. 220 & 32 & 03 & 118 & 50 & Brick & 2 & 1.63 & 0.06 & 90 & 3.2 & 18.2 & 0.6 \\
\hline Eastern Han & A.D. $25-220$ & 28 & 12 & 112 & 59 & Baked earth & 3 & 0.70 & 0.02 & 41 & 1.1 & & \\
\hline Eastern Wu & A.D. $229-231$ & 30 & 15 & 120 & 08 & Brick & 3 & 1.43 & 0.02 & 78 & 1.1 & 16.1 & 0.2 \\
\hline Three Kingdoms & A.D. $220-265$ & 28 & 35 & 112 & 21 & Brick & 2 & 1.19 & 0.02 & 66 & 1.1 & & \\
\hline Three Kingdoms & A.D. $238-251$ & 30 & 15 & 120 & 08 & Brick & 2 & 1.45 & 0.04 & 80 & 2.1 & 17.6 & 0.5 \\
\hline Eastern Wu & A.D. $222-280$ & 32 & 03 & 118 & 50 & Brick & 4 & 1.41 & 0.04 & 78 & 2.1 & 15.2 & 0.4 \\
\hline $\mathrm{Wu}$ & A.D. $272-274$ & 30 & 15 & 120 & 08 & Brick & 3 & 1.56 & 0.02 & 86 & 1.1 & 17.1 & 0.2 \\
\hline $\mathrm{Wu}$ & A.D. 275 & 30 & 15 & 120 & 08 & Brick & 3 & 1.47 & 0.04 & 81 & 2.1 & 17.1 & 0.4 \\
\hline Western Jin & A.D. $280-289$ & 30 & 15 & 120 & 08 & Brick & 3 & 1.21 & 0.01 & 67 & 0.6 & 14.7 & 0.1 \\
\hline Western Jin & A.D. $265-316$ & 31 & 22 & 119 & 48 & Brick & 2 & 1.26 & 0.05 & 69 & 2.7 & 14.5 & 0.5 \\
\hline Western Jin & A.D. $291-299$ & 30 & 15 & 120 & 08 & Brick & 2 & 1.38 & 0.04 & 76 & 2.1 & 14.4 & 0.4 \\
\hline Jin & A.D. $265-420$ & 28 & 11 & 112 & 59 & Brick & 2 & 1.06 & 0.05 & 58 & 2.7 & & \\
\hline Eastern Jin & A.D. $317-420$ & 32 & 22 & 119 & 28 & Brick & 3 & 1.49 & 0.07 & 82 & 3.7 & 15.6 & 0.7 \\
\hline Northern Dyn. & A.D. $477-499$ & 30 & 15 & 120 & 08 & Brick & 3 & 1.19 & 0.03 & 65 & 1.6 & 13.4 & 0.3 \\
\hline South.-Northern & A.D. $420-589$ & 30 & 21 & 112 & 12 & Grave brick & 2 & 1.21 & 0.06 & 67 & 3.3 & & \\
\hline Liang & A.D. $502-530$ & 32 & 03 & 118 & 50 & Brick & 3 & 1.44 & 0.08 & 79 & 4.2 & 15.7 & 0.8 \\
\hline Tang & A.D. $760-907$ & 32 & 22 & 119 & 28 & Brick & 3 & 1.06 & 0.03 & 58 & 1.6 & 11.7 & 0.3 \\
\hline Northern Song & A.D. $960-1127$ & 29 & 08 & 119 & 11 & Kiln brick & 3 & 1.06 & 0.02 & 58 & 1.1 & 11.4 & 0.2 \\
\hline Northern Song & A.D. $960-1127$ & 28 & 10 & 119 & 12 & Kiln brick & 3 & 0.93 & 0.02 & 51 & 1.1 & 9.9 & 0.2 \\
\hline Song & A.D. $960-1279$ & 31 & 20 & 121 & 10 & Brick & 3 & 0.91 & 0.03 & 50 & 1.6 & 9.8 & 0.3 \\
\hline Southern Song & A.D. $1127-1279$ & 29 & 17 & 117 & 11 & Kiln brick & 5 & 1.15 & 0.02 & 63 & 1.1 & 12.8 & 0.2 \\
\hline Southern Song & A.D. $1227-1279$ & 31 & 16 & 121 & 35 & Brick & 2 & 1.02 & 0.01 & 56 & 0.6 & 10.8 & 0.1 \\
\hline Yuan & A.D. $1271-1368$ & 28 & 08 & 119 & 11 & Kiln brick & 3 & 1.14 & 0.01 & 63 & 0.6 & 12.5 & 0.1 \\
\hline Yuan & A.D. $1271-1368$ & 28 & 10 & 119 & 12 & Kiln brick & 3 & 1.00 & 0.02 & 55 & 1.1 & 11.7 & 0.2 \\
\hline Yuan & A.D. $1271-1368$ & 29 & 17 & 117 & 11 & Kiln brick & 5 & 0.86 & 0.01 & 47 & 0.6 & 9.8 & 0.1 \\
\hline Ming & A.D. $1368-1661$ & 29 & 17 & 117 & 11 & Kiln brick & 3 & 0.82 & 0.01 & 47 & 0.6 & 10.4 & 0.1 \\
\hline Ming & A.D. $1368-1370$ & 32 & 03 & 118 & 50 & Brick & 3 & 1.24 & 0.03 & 68 & 1.6 & 14.6 & 0.3 \\
\hline Ming & A.D. $1368-1661$ & 28 & 10 & 119 & 12 & Kiln brick & 4 & 0.78 & 0.01 & 45 & 0.6 & 10.2 & 0.1 \\
\hline Ming & A.D. $1488-1505$ & 32 & 03 & 118 & 50 & Brick & 3 & 0.88 & 0.03 & 48 & 1.6 & 10.2 & 0.3 \\
\hline
\end{tabular}

1. Dynasty is a historical interval according to the Chinese chronology. SLA and SLO are north latitude and east longitude of sampling site. $N$ is number of samples used. $F_{0} / F$ is the ratio of the ancient intensity of geomagnetic field $F_{0}$ to the present day value $F$ in the laboratory. $S$ and $S_{0}$ are standard error of $F_{0} / F$ and $F_{0}$, respectively, i.e., $S_{0}=S * F$ (WEI, et al., 1980). $M$ and $S_{\mathrm{m}}$ are VDM and its standard error. $F_{0}$ and $S_{0}$ are given in $\mu \mathrm{T} ; M$ and $S_{\mathrm{m}}$ are given in $10^{22} \mathrm{Am}^{2}$.

2. For some dynasties only paleointensity data have been quoted from previous results (WEI, et al., 1983). 


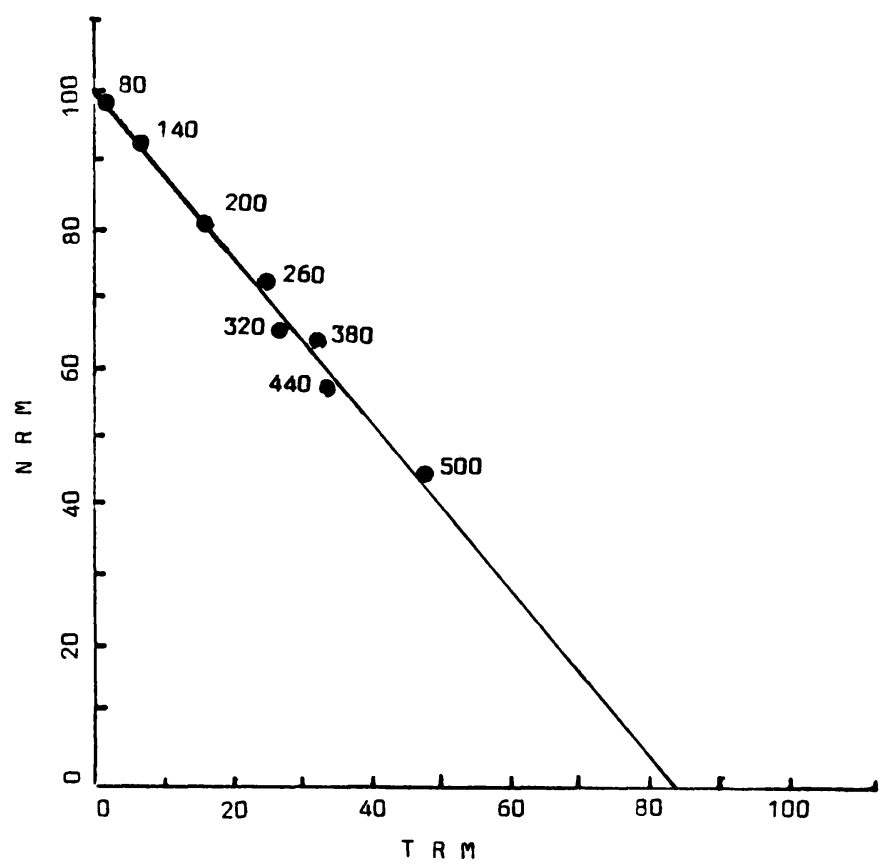

(a)

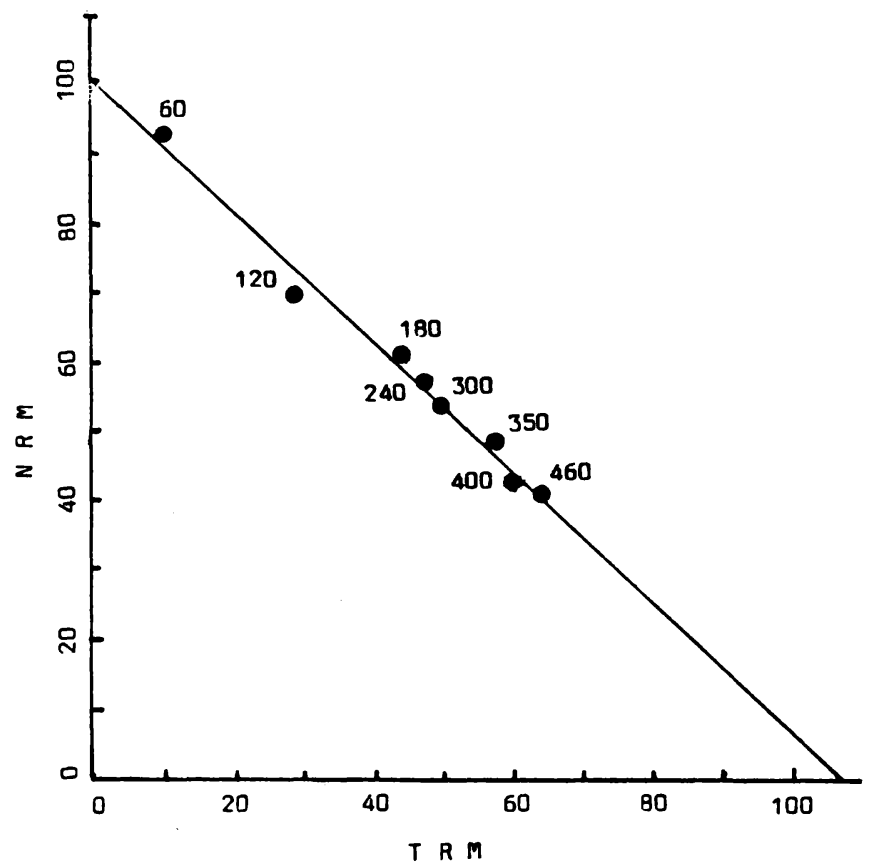

(b)

Fig. 2. NRM-TRM diagrams for samples from Shanghai, Southern Song(a); Dabaian, Northern Song(b); Hangzhou, Western Jin(c); Yixin, Western Jin(d); Jingdezhen, Yuan(e) and Anfu, Northern Song(f). Both NRM and TRM are in relative units. 


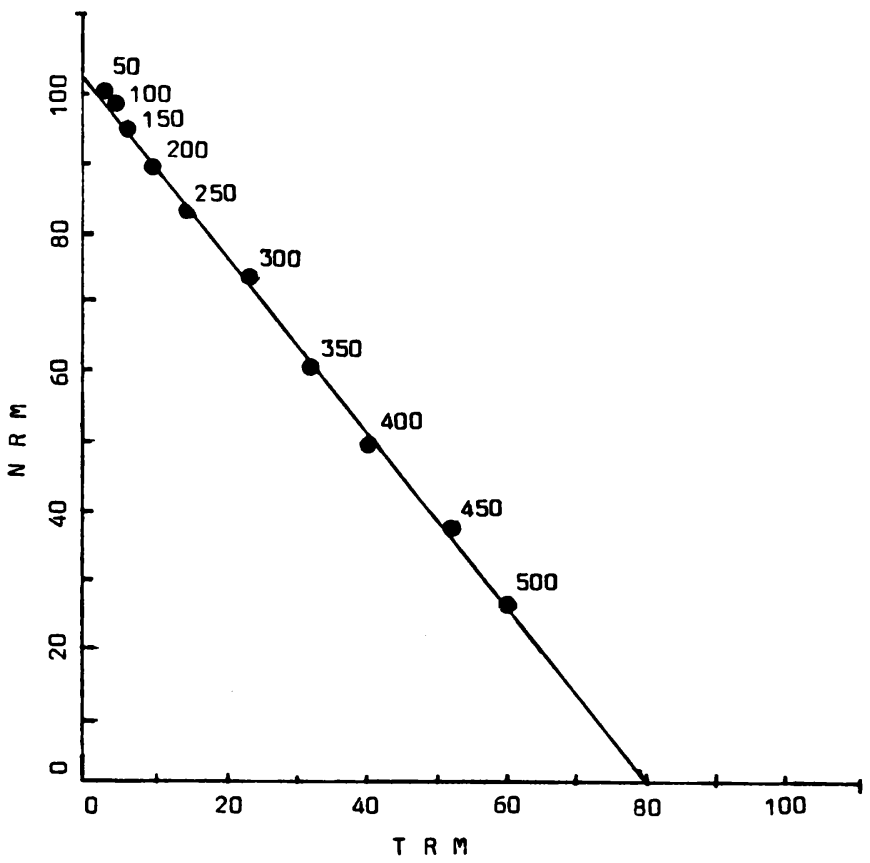

(c)

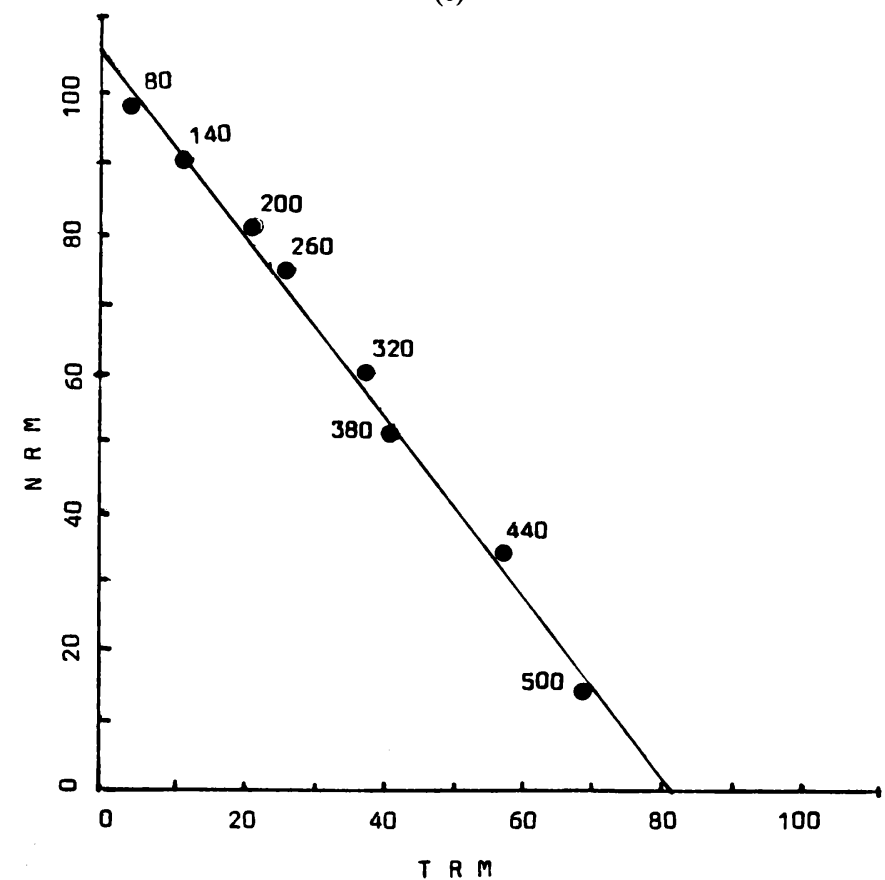

(d) 


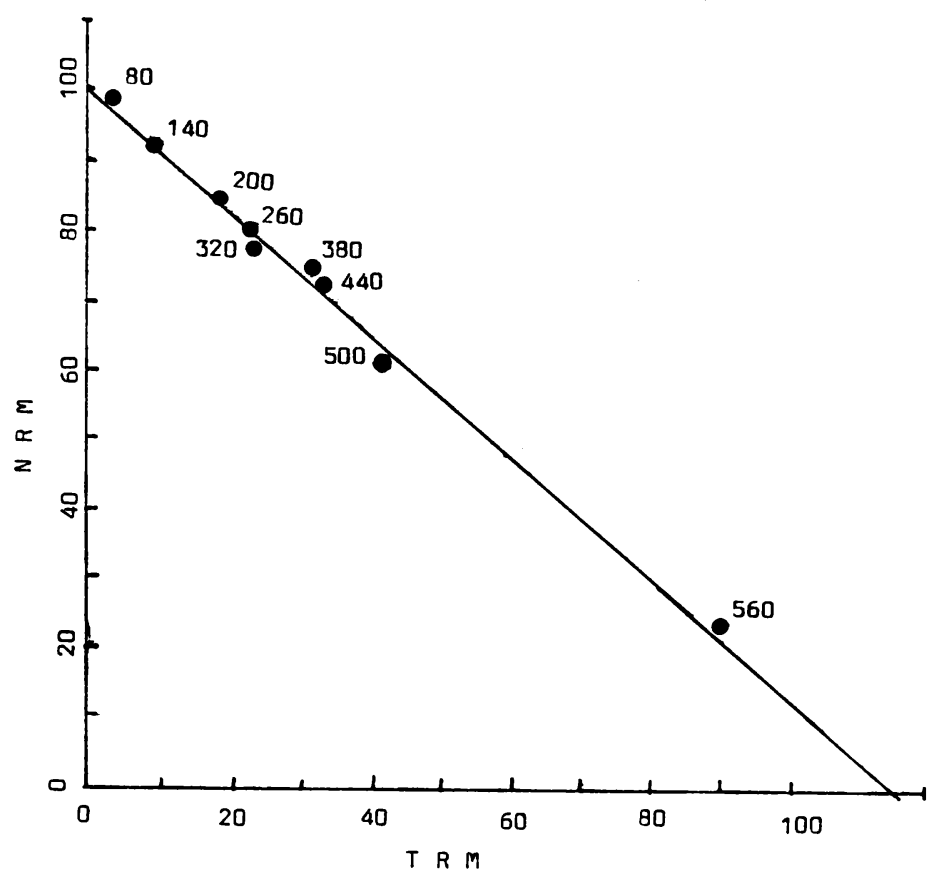

(e)

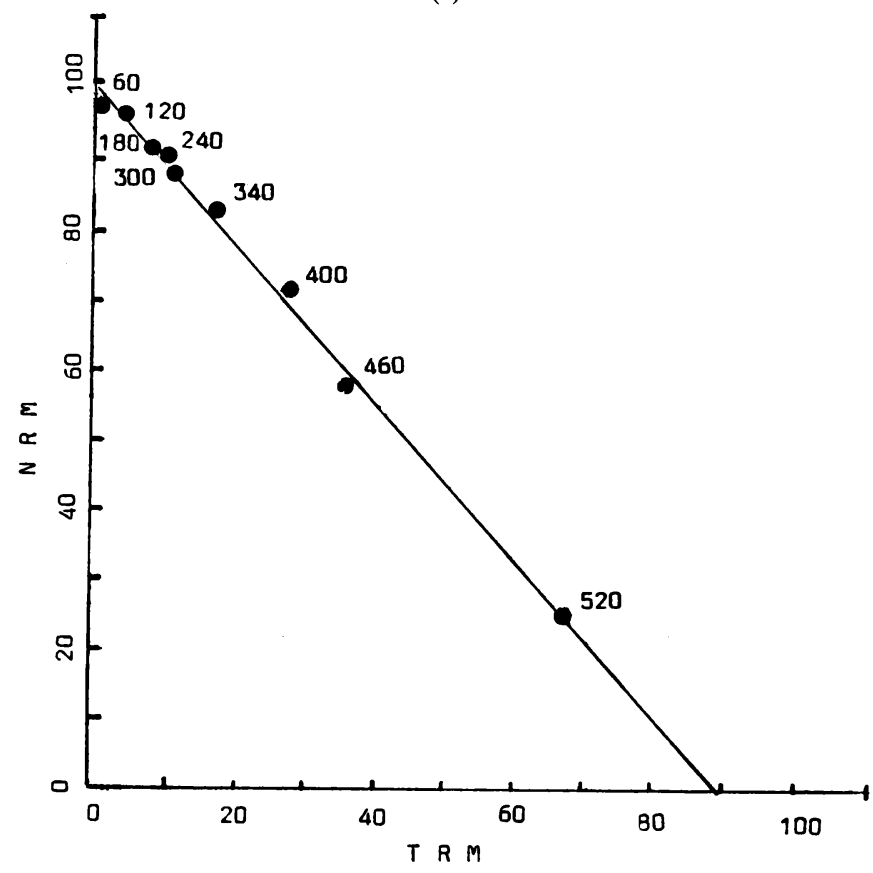

(f)

Fig. 2. (continued). 
afterwards. This general tendency of changes in intensity of geomagnetic field is undoubtedly true, even though the total error is about $20 \%$ when the effect of non-dipole field, experimental error, local geomagnetic anomaly and the error in the age of sample are all taken into account. It's interesting to compare these results with those for the Loyang region (WEI, et al., 1982a). It can be noticed immediately that they agree quite well with each other for the period from 500 B.C. to A.D. 1500 (see Fig. 4) in spite of the difference in latitudes between the two regions.

As for the earlier period, for example, 1500 B.C.-A.D. 500, the value of ancient intensity decreased reaching a minimum at about 900 B.C. and subsequently increasing till the maximum at about A.D. 500. Before this period the total intensity of geomagnetic field was close to the present day level, with possibly slight increase between 2000 B.C. and 1300 B.C..

When the results for China are compared with those for Japan (TANAKA, 1982) it can be seen clearly that both Chinese and Japanese data for the last 6500 years reveal the same major features, even though the difference in latitude and longitude of sampling localities are not negligible. Moreover, the data sets obtained from China and the Middle-Near East by using ceramics (WEI and AITKEN, 1982) display similar characters of changes in ancient intensity for the period 3000 to 1000 B.C. and 500 B.C. to A.D. 1400 .

In order to compare the new results of the present work for the southern part of China with the results of previous works for other parts, mainly Northern part of China, the Virtual Dipole Moment (VDM) was calculated and the variations of VDM with time are shown in Fig. 5. It is clear that all of the data agree that the magnetic moment of the Earth generally increased with time and reached maximum at bout A.D. 500. Then it decreased gradually to the present-day value. It is also evident that the variations of shorter periods exist superposed on the gradual variations during the whole period under discussion, especially during the last 3000 years.

\section{Conclusions}

The results of present work provide some new data of ancient field intensity in southern part of China, along the Yangtze River valley, for the period between 4500 B.C. and A.D. 1500. These data agree well with those obtained previously from other parts of China, mainly along the Yellow River valley. Chinese paleointensity data for the last 6500 years agree with the already proposed interpretation that the total intensity of geomagnetic field has a maximal value at about A.D. 500 and then decreased to the present-day value. Before this period the field intensity has a slight minimum at about 900 B.C. (see Fig. 3(a)). Thus, the total intensity of geomagnetic field has changed more than twice during the period of about 1500 years between 900 B.C. and A.D. 500 and by about $60 \%$ during the last 1500 years. 


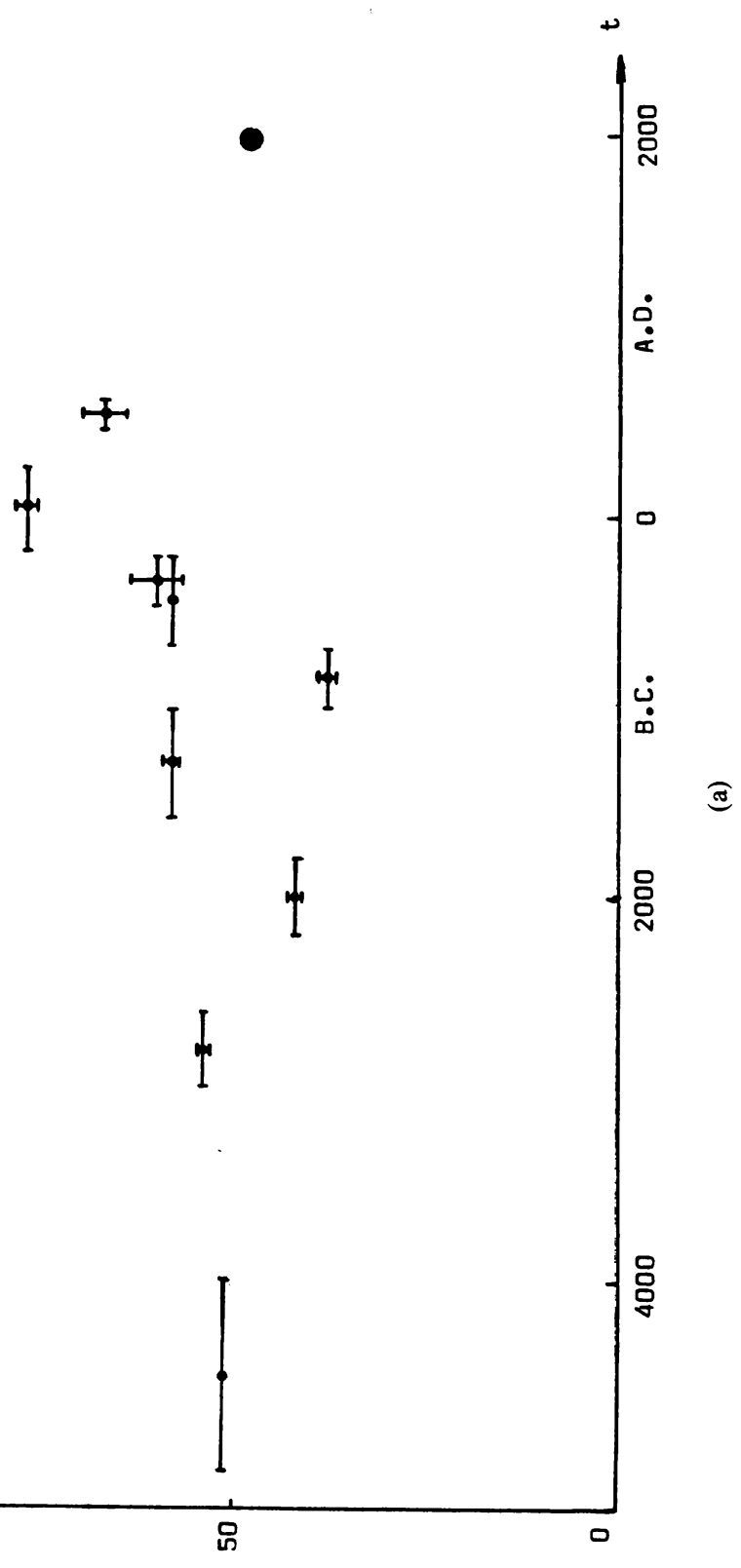




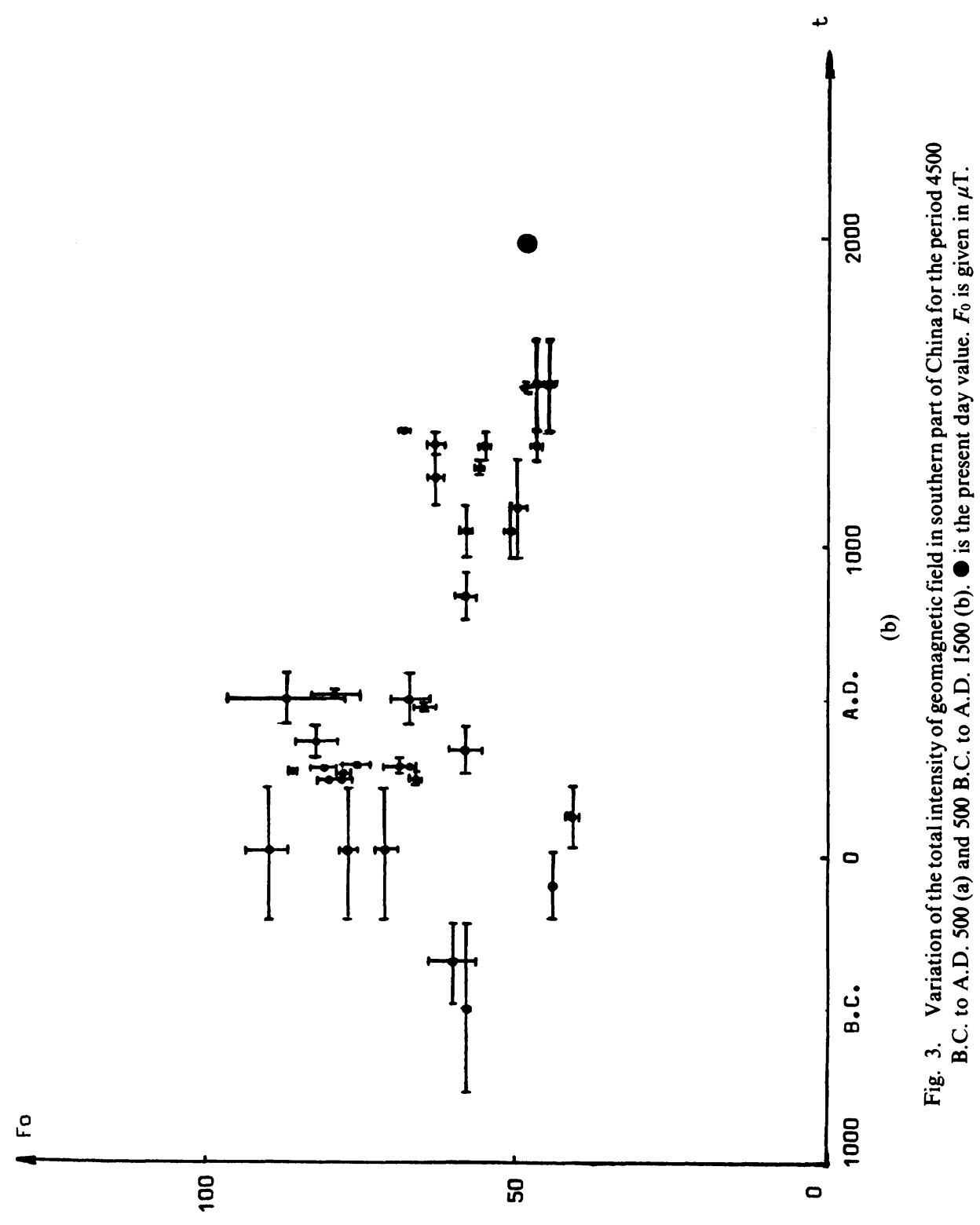




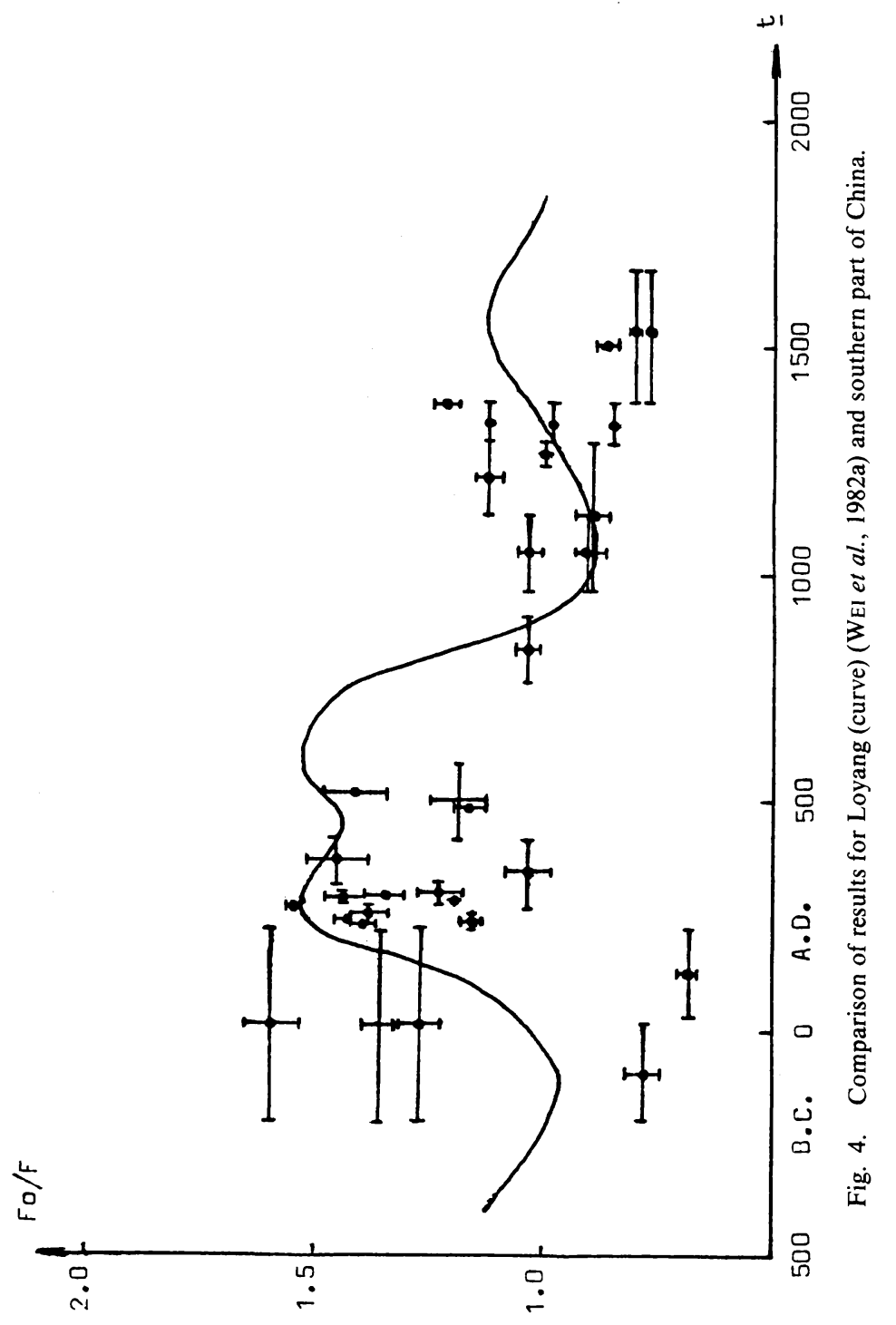




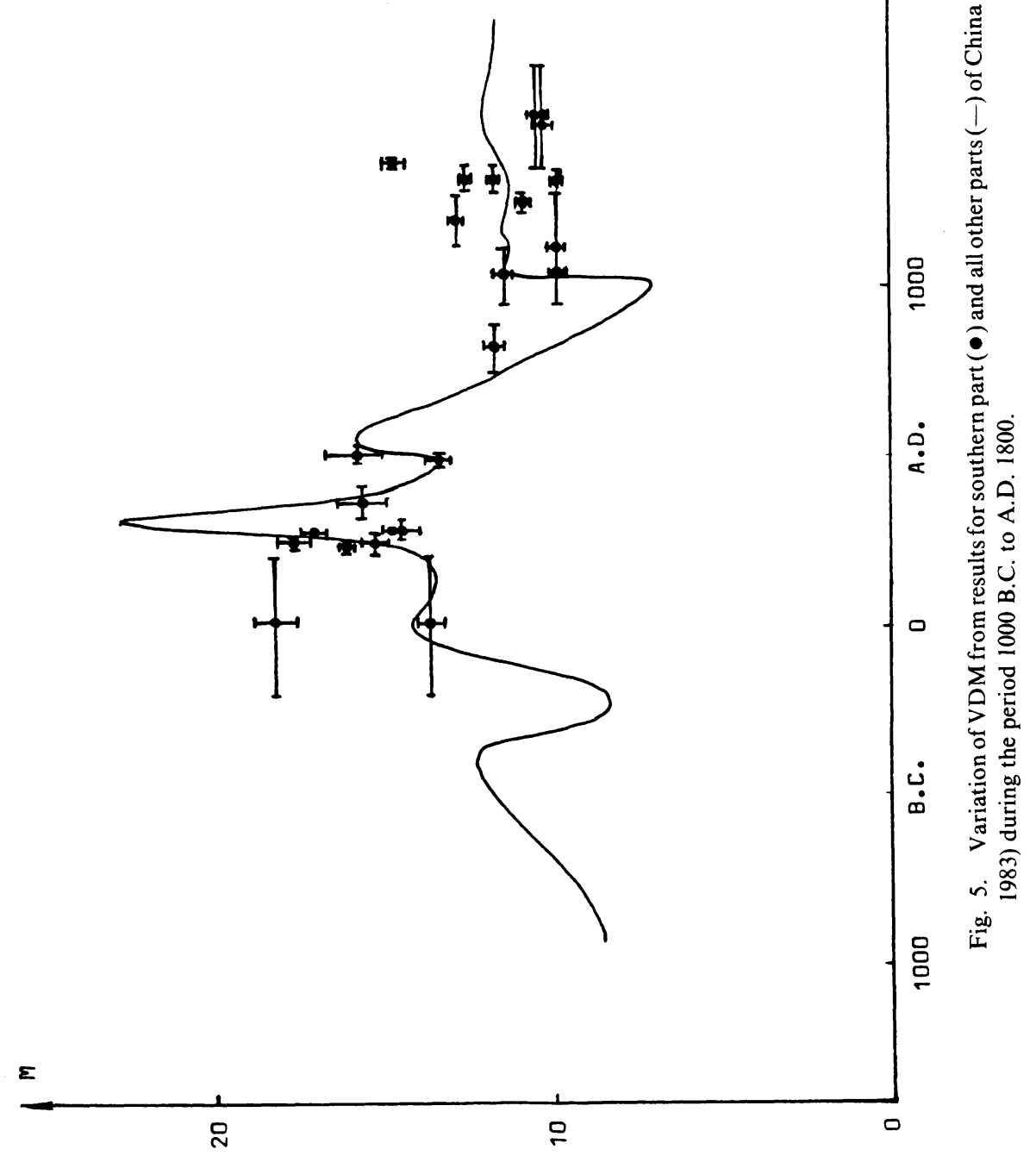




\section{REFERENCES}

DENG, H. H. and D. J. Ll, The geomagnetic field in Peking region and its secular variation during the last 2000 years, Acta Geophysica Sinica, 14, 181-196, 1965.

SHAw, J., Recent advances in archaeomagnetism, J. Geomag. Geoelectr., 37, 119-127, 1985.

TANAKA, H., Geomagnetic paleointensities for the period 6000 to 3000 years B.P. determined from lavas and pyroclastic flows in Japan, J. Geomag. Geoelectr., 34, 601-617, 1982.

Thellier, E. and O. Thellier, Sur l'intensite du champ magnetique terrestre dans la passe historique et geologique, Ann. Geophys., 15, 285-376, 1959.

WEI, Q. Y. and M. J. AItKen, The magnetic record carried in ancient Chinese pottery, Proceedings Internat. Conf. on Ancient Chinese Pottery and Porcelain, Shanghai, 1982 (in press).

WeI, Q. Y., D. J. LI, G. Y. CAO, W. X. ZhanG, and S. P. WANG, Archaeomagnetic research of Jiangzhai relic, neolithic epoch, Acta Geophysica, 23, 403-414, 1980.

WEI, Q. Y., D. J. LI, G. Y. CAO, W. X. ZhaNG, and S. P. WANG, Secular variation of the direction of the ancient geomagnetic field for Loyang region, China, Phys. Earth Planet. Int., 200, 107-112, 1981.

WeI, Q. Y., D J. LI, G. Y. CAO, W. X. ZhANG, and S. P. WANG, Intensity of the geomagnetic field near Loyang, China between 500 B.C. and A.D. 1900, Nature, 296, 728-729, 1982a.

WEI, Q. Y., D. J. LI, G. Y. CAO, W. X. ZHANG, and S. P. WANG, The secular variation of the inclination of the geomagnetic field for Beijing region, Acta Geophysica Sinica, 25, 644-649, 1982b.

WeI, Q. Y., D. J. LI, G. Y. CAO, W. X. Zhang, S. P. WANG and S. F. Wel, Archaeomagnetism of baked clays: results from China, in Geomagnetism of Baked Clays and Recent Sediments, pp. 138-150, Elsevier Science Publishing Company, 1983.

WEI, Q. Y., D. J. LI, G. Y. CAO, W. X. ZHANG, and S. P. WANG, The wandering path of virtual geomagnetic pole during the last 6000 years, Acta Geophysica Sinica, 27, 562-572, 1984. 